\title{
ProductMap: a proposal for knowledge organization in design education
}

\author{
Cassia Mousinho de Figueiredo, Ricardo Manfredi Naveiro \\ Universidade Federal do Rio de Janeiro \\ e-mails: cassiafigueiredo@hotmail.com; ricardo.naveiro@poli.ufri.br
}

\begin{abstract}
This paper aims to present a computational tool, ProductMap, developed to aid the design of new products. Such tool is based on the knowledge organization employed in the design by categories, in order to allow design students explore holistically the product he wants to conceive. The products and categories are visually organized in a representation structure called mind map that allows a product to link to its similar one by their attribute connections. To support the discussion about the gains through the use of the tool, we conducted a design exercise with design students, making use of the tool, to investigate whether there was an improvement in the process. The results are illustrated and discussed.
\end{abstract}

Keywords: product design, design knowledge, design education, mind maps.

\section{Introduction}

The product design activity demands much of its time searching for information leading to solutions for the project's defined problems. Design students or professionals seek information in various ways, whether in books, catalogues, websites, or even in the observation of similar products. More experienced designers already have a greater range of solutions derived from the design practice. This search for solutions is part of everyday life of the designers and is encouraged by design teachers.

In design education, there is a fact to be highlighted. Currently it has been noticed in the students a need for a more dynamic, multidisciplinary and integrated teaching. These young people, in general, also have a greater ability to handle several concurrent factors and knowledge and a more global view of the processes. This is a fact which fits very well with the everyday design: a multidisciplinary activity, involving several skills simultaneously seeking solutions that meet all the requirements in a balanced and efficient way.

In this paper it will be presented the ProductMap, a computational tool that is based on the organization of knowledge within design, with the aim to aid the design of new products. Design students may use this tool for acquiring knowledge in design and also to explore holistically the product they intend to conceive. ProductMap development involves the definition of categories as a way to structure knowledge and use of a computational tool that makes knowledge more accessible and dynamic. Furthermore, the computational tool creates a reusable knowledge that can be updated and expanded. ProductMap, as a tool for visual representation of knowledge, does not intend to replace but complement the students' and professional's research, as it concentrates knowledge coming from several sources: patents, books, catalogues, reports of their authors, product analysis.

The purpose of this paper is to organize the knowledge from previous projects to allow students to start a new project having at their disposal a visual library of previously generated solutions. That is, states that knowledge can be recycled to allow designers to employ their time in generating new solutions (EILOUTI, 2009), because prior knowledge is an intrinsic ingredient to the design (OXMAN, 1990). In addition, the goals of this paper are: to present ProductMap, its construction and the application of an exercise on which to base discussion about the improvement of the design through the use of the tool.

\section{Knowledge design management}

In everyday design, new projects are constantly made, design solutions are generated, and in most cases these solutions are not new. That is, it is employed a relatively large time in the project to research and reach solutions that have already been found previously, unknown to the designer.

The raw material of design is information. To transmit knowledge, you need it to be captured, recorded, structured, classified and released to be actually used, generating new knowledge. That is, the easy access to knowledge depends on its organization according to classification of criteria and terms of standardization used in the definition of the elements and concepts. The organized knowledge allows their reuse later, extending the range of solutions and reducing the time spent in the phase of idea generation.

Classifying is a way of structuring knowledge. A successful classification must permit the distinction in terms of a set, making them unique. The main rule for the 
development of a classification is that it is exhaustive and mutually exclusive (BAILEY, 1994), able to order a set of beings in small groups according to common characteristics that unite them, or differ from other groups (NUNES; TÁLAMO, 2009). One class consists of any number of elements (objects and ideas) having a common feature by which must be differentiated from other elements and which at the same time constitutes its own unit (TRISTÃO; FACHIN; ALARCON, 2004).

There are several ways of properly structuring knowledge, and this paper uses the classification by facets. In a faceted classification, subclasses are grouped into simple facets, each facet being the total number of subclasses obtained by the application of a particular principle of division (HUNTER, 2009). Briefly, a facet is a category, and a category is a set of properties of similar qualities, those properties satisfy the user's view of the same need.

This paper objective is not to define a rigid and definitive classification, but point categories, or facets, to organize knowledge and offer a vision of the product as a whole, which facilitates user access to knowledge through a search for models, materials, characteristics and solutions.

\subsection{Knowledge in the designer education}

The design process involves a great deal of knowledge from part of the accumulated experience by the designers during their professional life. The sources of knowledge vary from formal education to individual experience, including knowledge derived from similar cases (NAVEIRO; BRÉZILLON, 2003). In Knowledge Management, it is known by explicit knowledge the one that is easily outsourced and encoded in words, text, graphics or formulas. Since tacit knowledge is essentially the opposite of codified knowledge, it does not become aware until the receiver understands what is being transmitted. There needs to be understanding and contextualization to say that it is knowledge. Technically speaking, tacit knowledge is knowledge that is more strongly based on individual understanding, experience or the experience of the individual (BUSCH, 2008).

Learning and teaching design involves tacit knowledge. Professor acquired tacit knowledge about how to make design projects in their years of experience. By transmitting that knowledge to students, it should make it explicit, and this often occurs as a recipe or a step-by-step with well defined goals and deadlines. Tacit knowledge, for students, will come with time and practice.

During the development of a new product, designers must consider several factors simultaneously, such as: cost, time of production and launching; materials and available manufacturing processes; technical aspects; ergonomics features; viability; market, trends and sales; aesthetics features and even other factors such as transportation, inventory, and product display. The equalization of all these factors is what is usually called the design problem.

The more experience and knowledge the designer acquires greater tends to be their repertoire of solutions for the design project. Another way to gain this knowledge is through research of similar products and patents. The design solutions can also come from the observation of similar or different, but with some attribute in common, in search of information and inspiration about the use of materials, adequacy of cost, viable manufacturing processes, constructive and structural aspects.

\subsubsection{Teaching and learning design}

The design is a multidisciplinary field that combines knowledge and skills in three major areas: Arts, Sciences and Technology. According to Cross (1990), in formal education there is a sharp division between these areas, although they cannot be unlinked. However, the undergraduate education in product design in Brazilian universities, knowledge areas required for the development of a complete design - considering formal and technical aspects - are still taught in isolation. Students have difficulties along the way; they think of the design as a whole thing and see the product as a result of different fields of knowledge. They lack an integrated view of the product development process.

In design education, students are encouraged to seek solutions to design problems, which increase the complexity gradually throughout the course. In the early stages of the process, search tools and associated information are of great assistance. Additionally, students are increasingly seeking multimedia resources, and teaching only in the classroom does not meet their requirements anymore. It is essential, then, to change and relax the teaching methods allowing this expansion. About this, Bürdek (2005, p. 258) notes that

$[\ldots]$ in the '80s, the passage from the natural sciences to the humanities was a paradigm shift in design, in the '90s became evident the need for new guidelines determined by increasingly strong scanning. Also the need in practice to prove empirically design concepts (whether hardware or software) requires new methods.

\subsubsection{Contextualization of the design knowledge}

It is argued that the knowledge that has been generated in other projects, with a view to solving problems, can be reused in new projects of similar products or not. The importance of observation of other products and solutions as a way to feed new projects can be summarized by the statement of Lawson (2005, p. 122):

Each design, whether built or made, or even if just left on the drawing-board, represents progress in some way. [...] They are to design what hypotheses and theories are to science. They are the basis upon which design knowledge advances. 
Past experiences are fueling new projects in various ways. Eilouti (2009, p. 345) considers that the design theory based on precedent is well applicable to teaching. According to this theory, the main role of teaching design is to expose students to a rich repertoire of previous projects. The precedents of this repertoire serve as an essential starting point for new designs, and according to that author, "[...] avoid the problem of 'reinventing the wheel' and reach satisfactory design solutions with relative ease and speed".

Oxman (1990, p. 18) proposed a model based on previous projects that apply the reasoning associated with memory and argues that prior knowledge is an intrinsic ingredient to the design, and that

$[\ldots]$ it is an assumption of our work that the design is, in fact, a dynamic process of adaptation and transformation of the knowledge of prior experiences in order to accommodate them to the contingencies of the present.

The mind maps are gaining great importance for their way of visually representing and organizing knowledge, as well as the relationship between various concepts. The technique developed by Buzan (2002) allows registering the thinking creatively, flexible non-linear as in the mind (OKADA, 2004). The use of the mind with its ideas and abstractions, linking the attributes, characteristics and stages, is allowed by the flexibility of mind maps, and therefore it is believed that a mind map is the easiest way to introduce and extract information from the brain, mapping ideas creatively and effectively.

The advantages of using mind maps, according to Buzan (2002), in relation to learning and natural functioning of the human mind are: (1) they facilitate the retrieval of data, helping the individual to learn, organize and store large amounts of information and (2) they allow to classify the natural forms of information that will permit instant and easy access, (3) they work with the needs of the brain in ways similar to their functioning, ie, through imagination and association, since the brain works with sensory images and connections, and does associations which radiate; (4) their organization from the relationship between concepts, composing a chart that radiates is similar to the memory, because the human mind has greater ease to recall a drawing, a keyword or information organized in a genealogical way.

Bürdek (2005) argues that Mind Mapping software allows multimedia management (text, images, movies, music, etc) that leads its users to new structuring of problems. The interactivity of this method allows a description of the multifaceted problems and opens, therefore, a high potential for innovation. That is, the mind maps may combine various types of representation of information simultaneously.

Some recent scientific studies address the use of mind maps as superior to traditional ways and linear transmission of knowledge and understanding. In relation to its use for the design, Kokotovich (2008) states that the visual representation of ideas helps students better understand and structure the problem in the early stages of the project. His research showed that the use of non-hierarchical mind maps allowed students to have a holistic view of the design problem and hence a solution as all their attributes and the relationships between them were explicit.

Dhindsa, Kasim and Anderson (2011) presented a comparative study about the effects of a traditional teaching method and a teaching method based on the use of mind maps. The results were significantly higher among students who attended the class elaborated with mind maps, regarding general and more thorough understanding of the proposed content.

Mind maps, because of their ability to visually represent information, can be used as an aid in teaching the explanations, preparing summaries and notes. In design it can be used as a presentation tool, to support the implementation of brainstorming, to structure and understand design or to organize ideas in the early stages.

\section{Construction of a knowledge-base}

Organizing knowledge is essential to permit its reuse. From each new project, much knowledge is generated, not only for the designer, but new solutions and attributes can be reused in new projects. To make this knowledge accessible in a practical and visual way, we propose a classification for the user to have a starting point for his search.

This paper also proposes to introduce ProductMap tool, which can be defined as a base where you store information, in a structured way, the solutions that have already been generated in previous projects may support the teaching and development of new projects. Among the types of knowledge representation, we opted for a faceted structure, based on six categories. Visually, the type chosen to structure and present the tool to the user is the mind map structure, visual by its nature and hypertext linked among similar elements, it allows intuitive use.

\subsection{A faceted classification for a computational tool}

ProductMap features six categories, or facets, through which the user can access a product and see its relation with others that share one or more attributes in common: author, application and class, materials and manufacturing processes, main components, functions and design solutions. Categories were chosen to ProductMap considering not only the classification accuracy and availability of information, but especially those with which students and design professionals were more familiar with. The facets are set below.

Author: It is undeniable the importance of referencing the designer of a product, even though this field is not part of the classification of a product. Moreover, the user can 
search all copies of the same author through this field, which facilitates and expands the search. Some models are also known by their manufacturers, as these are great references in the furniture market, such as Herman Miller and Kartell. In such cases, you can include the name of both to facilitate the search.

Application and class: This category refers to the class of the product and its usage, that is, its application. Application is the utilization or the usage that is given to a product; class is a group of people, animals or things that have one or more similar attributes. It is in this category that is differentiated and classified what is a chair, a bench, a chaise longue, and so on. As for the application, a chair, for example, can be for residential, office, or commercial environment, external or internal use, among others. There are basically two aspects that differentiate the application of a chair from another: the components and the shapes. The form suggests the posture you assume and therefore it indicates its use.

Main components: The parts that make up a chair, for instance, are able to differentiate it from a bench, or a stool, for example. Backrest, seat, arms, legs; casters differentiate products among themselves and can assist in the search for similar specimens, with the same structure. The World Intellectual Property Organization (WIPO) lists the essential components for each type of specimen of furniture. From these components, the materials and manufacturing processes are given, visually arranged as a subclass of the main components.

Materials and manufacturing processes: In this category are referenced materials which are produced with the main components of the product. This information is the most relevant to designers. To define the materials and manufacturing processes of furniture, one should obtain this information from the designer or the manufacturer. In the case of historical pieces that are no longer produced, this information is obtained from patents, books and furniture design history, catalogs, or the analysis of models.

Functions: In design, it is considered that an industrial product must meet one or more requirements of its users, and what satisfies these needs are the product functions. One of the distinctive features of the design, in relation to other areas of creative activity, is purely the product of the creation of the designer that should have at least one function, a practical purpose. ProductMap displays the functions that have more relevance to the product design. The function analysis indicated that the designers of the products, together with their respective design solutions, can feed the early stages of projects from other designers.

Design solutions: Developing design solution is the goal of the designer's work. From the determination of the main components of each product, and the roles they play, it is possible to establish a relationship between them. It develops a solution that can be adapted to another context. For example: a hinge used on the door of a closet to meet the open and close function can also be applied to a table top you want to zoom in or out according to the space available. This is one of the greatest contributions of ProductMap as it provides and explicit, especially for students of design, the solutions to each problem and functions that make up the design of a product.

\subsection{Building a knowledge base}

\subsubsection{Tools to contextualize the knowledge}

With the categories and scope of the collection defined, it was necessary to find a tool in which that knowledge was organized and made available to users. The ability to present contextualized information in a more visual and dynamic way, and allowing an intuitive use, led us to the choice of mind maps as a representative structure for ProductMap. Nevertheless, mind maps comprise well the faceted structure that the tool requires. Although initially this structure may cause surprise, since part of our education was geared to teach us to transmit information in a linear fashion (BUZAN, 2002), the mind maps are very intuitive and similar to our memory. There are many available pieces of software for building mind maps. These pieces of software have a structure that is based on a central concept, the main node, where the attributes belonging to the same category and lines represent connections to all of them that make up a product and other related products.

The selection of applications for experimentation was based on the flexibility, ease of use and the possibility of inserting images. All of them are commercial and were evaluated on their trial versions. The software PersonalBrain ("The Brain") 7.0 Pro was chosen to prepare ProductMap to be dynamic, allowing insertion of images, besides being simple and having an intuitive interface for the user.

Each core concept, the main node, can be attached an image that can be easily viewed by passing the mouse cursor over it. From a central concept, other concepts can be associated according to the relationship between attributes, linking them together or with other models, expanding exponentially the mind map, or "brain".

\subsubsection{Selection of the initial design collection}

In order to visualize the characteristics and potential of the tool ProductMap, some specimens were selected: furniture. The line of furniture was chosen for two reasons: there is greater availability of standards issued by official agencies that assisted in the structuring of this base and this sector has great relevance to industry in Brazil. The furniture design is an area of great importance for the Brazilian production and one of the few that handle the 
export of durables. The chair was chosen as the product example to compose the initial collection for being one of the most common among designers and which are developed a multitude of solutions in terms of structure and materials. It is the most common object in the history books of the history and design of furniture, and they can be drawn a timeline.

"Chair" can be understood as a seat with back support to a person. This generic definition can be completed stating that the object is a chair for the rest of the body part in the sitting position, which in itself sets its primary function: allow sitting. According to the WIPO, chairs are composed of: legs, support, arms, footrest, headrest, casters (WORLD..., 2011). Among these components are connecting elements, constructive solutions, functions, various materials and suitable production processes. These are the solutions developed by the designers that can be reused in other projects for new products.

The chairs that make up the initial database of ProductMap are mostly design signed by awaken curiosity in the larger public, but prioritizing the use of practical relevance with some kind of innovation. The goal is to show its innovative features, materials used and principles of solution that can be leveraged in future projects.

A significant part of this research work has focused on the search standards and other references that addressed the categories defined with clarity and lowest possible room for doubt, it should be a classification structure. Standards and official ratings agency unify the terms. However, there is a rule or set of rules that solely includes the full range of furniture and elements that compose them. The sum of the ratings of ABNT (Brazilian Association of Technical
Standards) and WIPO seeks to eliminate or at least reduce the gaps that may exist.

For models that are presented in the base, the search covers patents, books, catalogs and websites of the manufacturers, reports with the author's own observation of models in showrooms, exhibitions and standards.

ProductMap starts from an initial collection made up of a number of examples of furniture, with many features and materials. The criteria for selection of models that comprise the initial collection were: relevance, degree of innovation and access to patents and reports of authors and theorists on the models.

\subsubsection{ProductMap overview}

This section is intended to provide an overview of the operation and interface of ProductMap, the process of adding new models and the classification which they are subjected. The whole structure of the tool comes from a central node, "ProductMap", to which other nodes are subordinated, each one corresponding to a model in the collection (Figure 1).

When the user accesses the tool he/she can do a search through the model name or any category. The fitment is displayed and the user may continue the search, choosing a category, a class or a subclass. Figure 2, which records a ProductMap screen, shows the attributes related to the categories defined and a comprehensive view of each fitment. For the user to find a model, the tool is supported with an easy search mechanism placed at the bottom. Figure 3 is a simulation of visualizing the solution of the same stacking chair. With this figure it is possible to see that

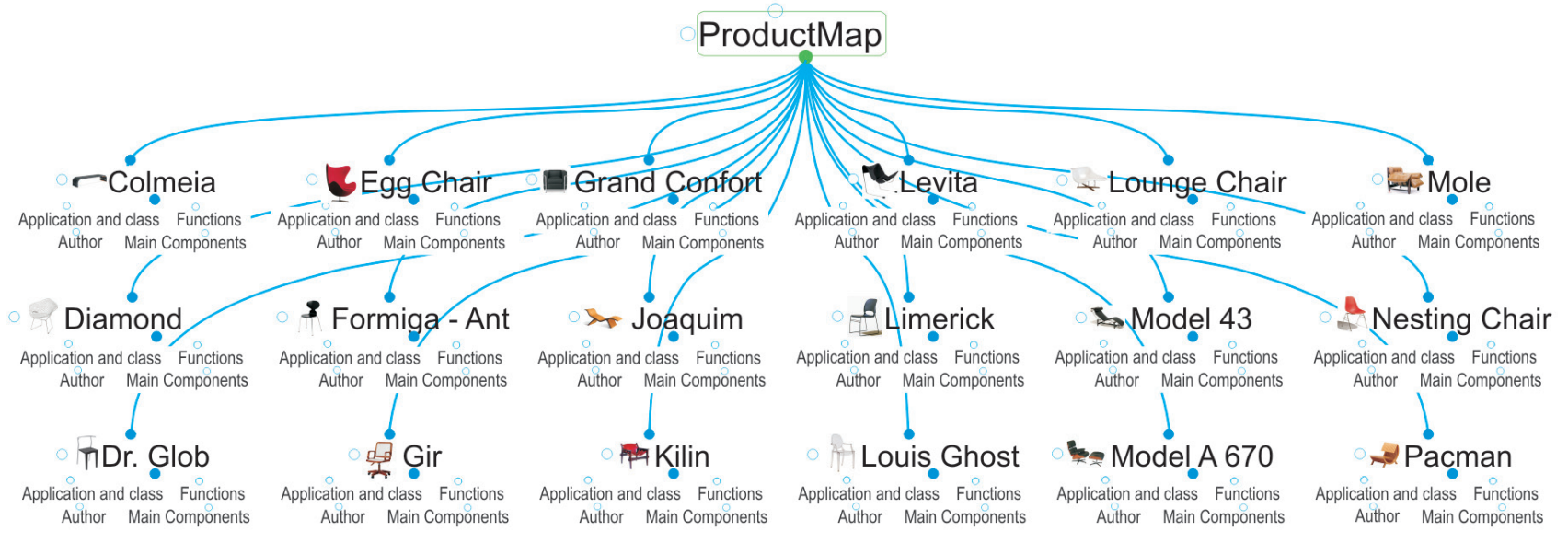

Search

Figure 1. ProductMap overview screen. 


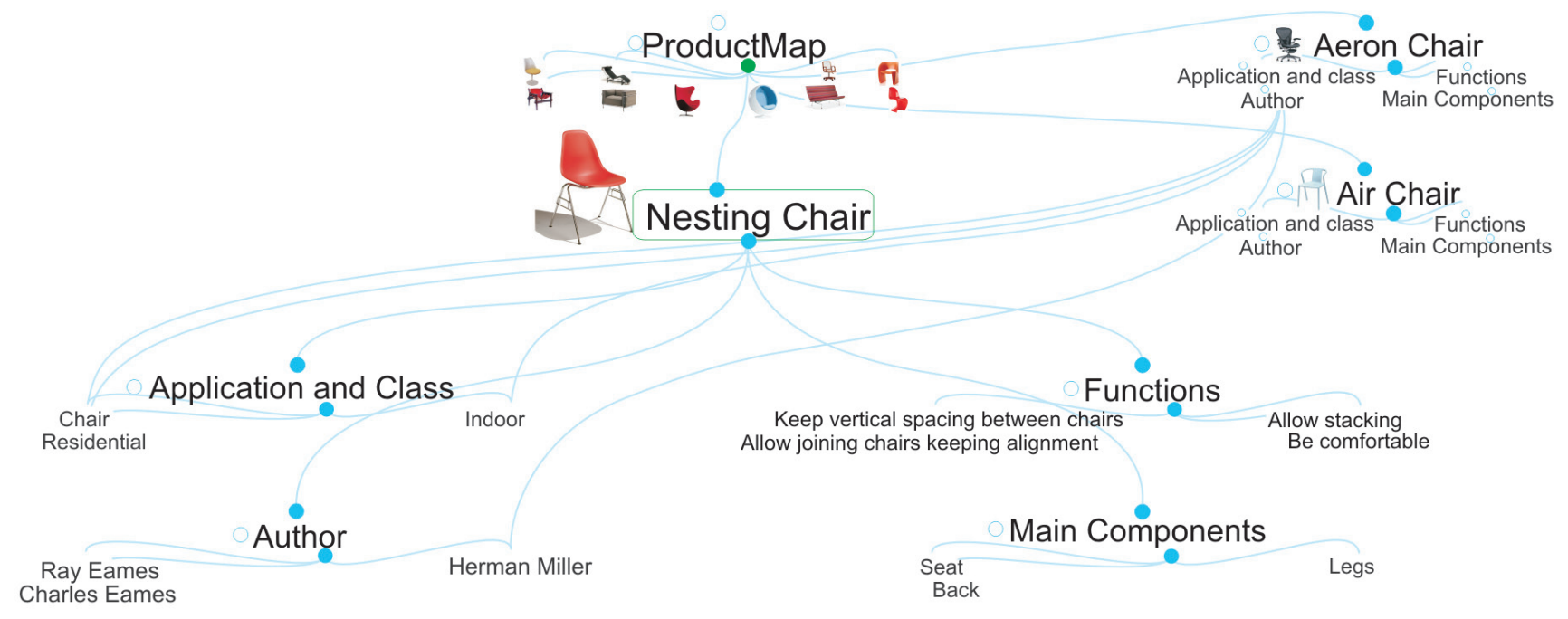

Figure 2. ProductMap, Nesting Chair screen.

the contextual information is formed by text and graphic images developed for this purpose.

The constant expansion of ProductMap is based on inclusion of new models of furniture. The moderator should review all the material raised for that model before starting sorting. When necessary, images or graphics are produced to spell out some better functional aspects of the product. Designers can collaborate including their products through a collaborative platform.

\section{Applying a design exercise using ProductMap}

To observe how less experienced designers would behave in front of a tool that aims to organize and facilitate access to knowledge, we applied a design exercise with students of the second year of Design bachelor degree, with experience in project and in the use of mind maps. Students were divided into groups which underwent a design exercise, and one of the students accessed ProductMap and the other did not. The exercises were evaluated by three professionals, who attribute concepts to four relevant questions to the project requested in order to generate quantitative results and foster a discussion about the characteristics, the quality and designs.

The purposes of the application of this exercise were: to evaluate the benefits of using the tool by students in preparing their projects and if there was an improvement in the project using the tool, generating quantitative data that fuel a discussion about the validity of using the tool; to observe students' behavior when accessing the tool, in terms of fluency in the use and enjoyment of all its features; to verify if there is evidence to prove whether or not there is inhibition of students' creativity, since the tool offers a range of ready, viable and already performed solutions.

\subsection{The protocol study}

The exercise consisted in designing a chair made by 28 students for two hours. The purpose of the exercise was to develop a stackable chair for a person and indicate in writing the material that would be suitable for the project. It has been suggested that students do two orthogonal views and drawing showing another stacking. These drawings were done by hand, without the aid of drawing instruments. Of all students, 21 used ProductMap during the project and 7 did not. The group of students who have not accessed ProductMap is listed as Group A, and the other one will be called Group B.

Quick projects have the advantage of lasting only a lesson and allow further discussion with the teacher and other students. The disadvantages are the difficulty in assessing the viability and lack of formal design and precision. The fact that it was a quick project prevents further discussion on technical and economical viability, as well as ergonomic and user testing, that would require well-designed prototypes and models.

Group A students did the exercise in a traditional classroom, and could access the internet through their mobile phones or tablets. Group B students were taken to a classroom with individual computers in order to access the online tool while performing the exercise. Students were asked to use stacking solutions suggested only in ProductMap. 

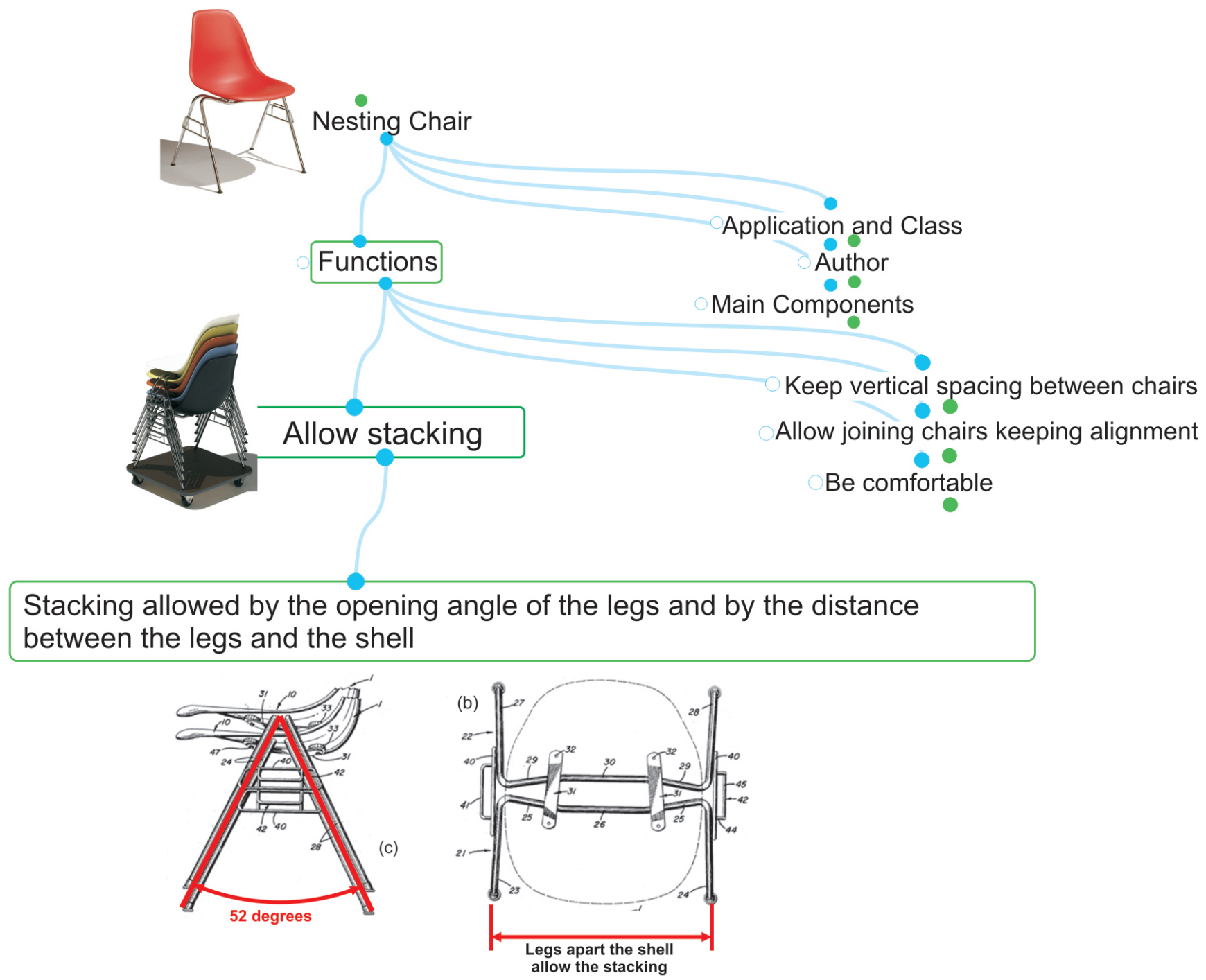

Figure 3. ProductMap; Nesting Chair solutions screen.

During the exercise, Group B students were observed in relation to the use of the tool, and showed no difficulty with the language of mind map with which they were already familiar. As expected, students assimilated using ProductMap as a step search of inspirations and solutions, replacing access to search engines, which they used in other designs as an unstructured search way. Group A students showed difficulty in visualizing the stack function, even with the possibility of accessing search engines on the Internet. It was observed that these students requested more attention from the teacher than the other groups.

In order to compare the designs of Groups A and B, we requested an evaluation to three design professionals with experience in the field and who already knew ProductMap previously. These evaluative concepts should assign to the requirements set for each of the projects. At the end of the evaluation, it was intended to grade each project, to try to measure the expected benefits from the use of the computational tool.

The judges received the 28 digitized designs and guidelines for the evaluation that focused on questions and evaluation criteria. They also provided information about the objectives of the exercise and how it was conducted. All drawings were scanned and sorted at random, with no indication.

The evaluation was done through an online questionnaire, for its practicality and reliability, consisting of a closed question to which the judges should give a concept of five: (1) very poor, (2) poor, (3) regular, (4) good, (5) excellent, which corresponds to a score from 1.0 to 5.0. It were defined four relevant requirements to the exercise to be respected by the judges in each project: (1) compliance and quality function to allow stacking, (2) technical feasibility, (3) the 
proposed material, (4) degree of innovation. Each of these concepts should be considered as it follows:

- (1) Solution: How does the design attend to the function of allowing the stacking? This question aims to evaluate how the chair is stacked. If it really stacks, if it could have been made small changes to allow stacking, if this stacking is practicable, or, in short, if it stacks but it could have been done better;

- Technical aspects: According to the proposed design, in which degree could this project be executed? This is a very important criterion in the design and it is always discussed and evaluated by teachers;

- Proposed material: It also refers to a technical viability, and also the consistency, suitability between the material proposed and the form presented by the student in terms of strength, workability and desired appearance;

- (4) Innovation: This item is the most subjective. To assess whether the use of a tool inhibits or helps designers to innovate in their forms. In this aspect, the judges, who previously knew ProductMap, should verify whether the student was inspired by the chairs presented - or another known in the market - or if he or she was unable to make it differently and made a copy.

\subsection{Results}

At the end of the interview by three judges, it came up the step of generating the results. The arithmetic average of each item divided by the groups can be checked in Figure 4. The assessment can be divided into four to more clearly present their results. The average of each question had numbers next to each other and similar to the overall final average, which was 2.41 points for Group A and 3.38 points for Group B.

In assessing the capacity and quality of the function to allow stacking, Group A had the final average 2.28 points, while Group B was 3.66 points. In response to the technical

\section{Evaluation results}

\begin{tabular}{|c|c|c|}
\hline Stacking Solution & $\begin{array}{l}\text { A } \\
\text { B }\end{array}$ & $\begin{array}{l}2,28 \\
\quad 3,66\end{array}$ \\
\hline Technical Aspects & $\begin{array}{l}\text { A } \\
\text { B }\end{array}$ & 2,55 \\
\hline Material & $\begin{array}{l}\text { A } \\
\text { B }\end{array}$ & $2,573,42$ \\
\hline Innovation & $\begin{array}{l}\text { A } \\
\text { B }\end{array}$ & 2,27 \\
\hline Total Judgement & $\begin{array}{l}\text { A } \\
\text { B }\end{array}$ & 2,41 \\
\hline
\end{tabular}

Figure 4. Evaluation results by category. feasibility of the chair, the Group summed 2.55 points A and Group B, 3.41 points. The choice of material for each subject received 2.57 points in Group A and in Group B, 3.42 points. Finally, the degree of innovation was evaluated with an average of 2.27 points for Group A and 3.01 points for Group B. Some aspects draw attention during the evaluation and its results, to wit:

- Innovation was the item with the lowest score for both groups, being 2.27 points for A and 3.01 for B;

- The overall averages for the technical feasibility and choice of material were practically the same, with a difference of 0.01 points or 0.02 for both groups;

- Nine students, or $32 \%$ of total general, suggested transparent materials such as polycarbonate and acrylic. Judges noted that for most of these models that was not the best choice of material;

- Means for category concentrated between 2.27 and 3.66. Considering that the average potential was between 1.0 and 5.0, it is observed that there was a wide range in the result;

- The item related to the stacking solution showed the greatest difference between the groups, with an average of 2.28 for Group A and 3.66 for Group B;

- Compared to the pre-defined concepts, it appears that the overall average Group A got a result (2.41 points) between "poor" (equivalent to 2.0) and "regular" (3.0), while group B (3.38 points) was between "regular" (3.0) and "good" (4.0).

\subsection{Results analysis}

It has been seen that the averages of Group B were higher, although not great. The major difference among the averages was stacking solution proposed by the students: 2.28 and 3.66 for groups $\mathrm{A}$ and $\mathrm{B}$, respectively. Comparing the final averages, 2.41 and 3.38 for Groups A and B, respectively, it is suggested that there was an increase in student achievement using the tool ProductMap.

Figure 5 presents four scattergrams that show graphically the distribution of students' test scores, the correlation between the category and final average. Group A is represented by red dots, and Group B is represented by blue ones. For these graphs it can be seen that even with a difference of subjects in each group, those that correspond to Group A are concentrated between grades 2 and 3 ("poor" and "fair", respectively), with few exceptions. The lowest ratings for overall grade are all regard to Group A and the highest scores belong to Group B.

As the average final grades consider innovation, the potential damage caused by inhibiting the creativity of students in Group B did not affect the completion of a project comparatively better. On interference to the use of the tool on the creativity of students, it can be seen that the lowest scores of both groups were in the item innovation. 

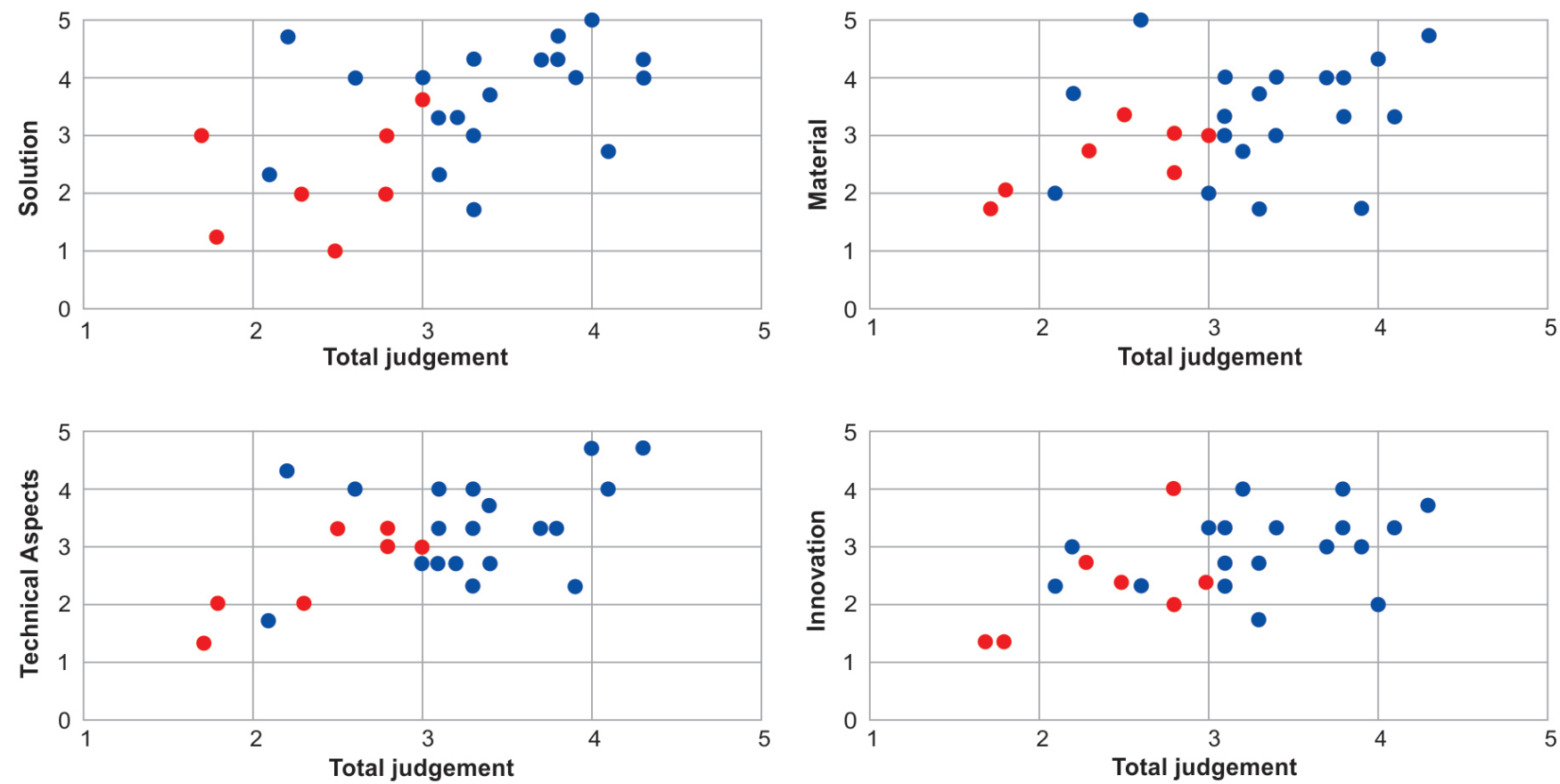

Figure 5. Scattergram for the means of "Total Judgment" and the four scoring categories.

Some students in Group B showed difficulty in untying the shapes of chairs displayed, generating formal concepts, initially very similar. It was shown to them that there are chairs of renowned authors who share the same solution, but they have distinct shapes. It was argued that the use of the same solution should not be seen as a factor inhibiting creativity, but the incentive to step forward.

To illustrate the issue of creativity, it will be cited two projects of Group B. At the end of the completion of the exercise, some students spontaneously commented on the chairs which they drew more attention for its forms and solutions, justifying the formal party chosen for their projects. Figure 6 shows drawings corresponding to two projects. Design 17 inspired by the Louis Ghost Chair, Philippe Starck, obtained as average 3.1 points in the evaluation, and his lowest grade was precisely in the category innovation (2.3). The design number 26 had also been strongly influenced by another chair: the ZigZag by Gerrit Rietveld. This design had the final average 3.8, one of the highest in Group B, and 4.0 points for creativity.

All averages in group B were higher, although they have not been great. Comparing the final averages, 2.41 and 3.38 for groups A and B, respectively, it suggests that there was an increase in students' achievement. Whereas the average final grades consider innovation, the possible harm caused by the inhibition of the creativity of students in Group B did not affect the completion of a project comparatively better.

\subsection{Discussion}

Due to its contextual nature and structure of mind maps, it is stated that the tool ProductMap, for didactic purposes, could be, besides a visual tool to aid early stages of the design, a model for other similar tools. The tool could also be used as a model for other purposes, namely:

- To assist teachers during class, thanks to its visual appeal, it allows submitting images to the students to support the explanation of a certain shape, material or solution. And to allow the teacher to externalize the knowledge he wants to transmit for the students, in a visual and integrated way;

- To inspire the organization of knowledge in a contextualized way, to be followed by designers during the stages of analysis and understanding of the design problem (as suggested KOKOTOVICH, 2008), or to outsource ideas among members of a team;

- To organize the technical memory of the design team, in a company, using a more dynamic and efficient approach than the usual reports and fact sheets. It is similar to a proposal drafted by Muller (2001), and should be developed by the team for archiving previous projects;

- Finally, as a template to prepare knowledge bases in other areas of the design, besides furniture. 


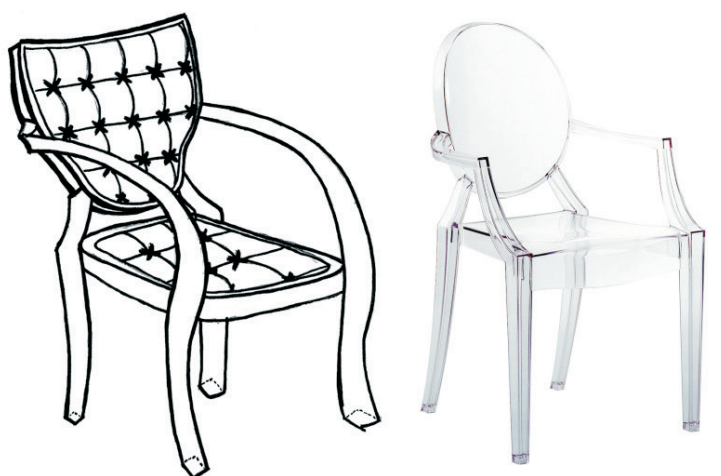

Design 17, inspired by Louis Ghost armchair
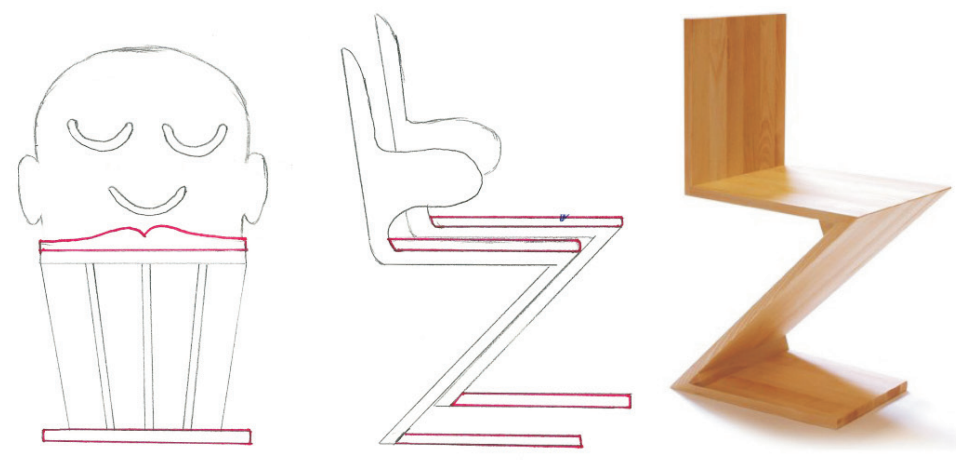

Design 26, inspired by ZigZag chair

Figure 6. Two design exercises examples.

About the aid that the tool can offer teachers, it can be illustrated with the application of exercise with the students in Group B. After the development of the chair project, some students asked the teacher to comment on the materials and forms chosen. To evaluate the feasibility of stacking, or the choice of material, for example, the teacher showed a chair with some solution, form or similar material to enhance understanding of the students, instead of searching images on websites.

The grade average does not seem to be very impressive, even in the case of Group B, which was between "regular" and "good". Evaluation of exercises comprised five alternative concepts for each aspect. Hill and Hill (2002) state that when the evaluation offers an odd number of alternatives, the respondent may adopt a conservative approach and choose the average degree ("regular") when in doubt, find it "safer" not having a strong opinion (neither positive nor negative). The fact is that this concept generates a number, in which case this evaluation corresponded to grade 3 , and that number greatly influenced the final result.

Measure the quality of a design is a subjective matter. But this should not invalidate the quantitative assessment done in this paper, because teachers design should assign grades to their students at the end of each project. The questionnaire was elaborated trying to reproduce a more grounded evaluation, in which the judge makes clear the design objectives and then assigns them a previously established degree.

More elaborated exercises, with a longer term and computerized presentation could better demonstrate the benefits of using the tool in the project's outcome, and would probably have a more expressive evaluation. However, this activity requires students' engagement and commitment not to use any other means beyond the research tool. But it is believed that this does not invalidate the conducted experiment, due to the results achieved in the comparison between the groups.

\section{Conclusion}

In this paper a knowledge base, ProductMap, was presented. This base, oriented with an emphasis on design and furniture, intends to organize and deliver knowledge to facilitate its access and reutilization. This tool was part of a $\mathrm{PhD}$ research and there is a proposal to make it available online to the public, and not be restricted to the academic environment, where users could suggest the inclusion of new models of furniture to ensure the expansion of the knowledge base.

It is hoped that this tool can assist the education through its way of integrating different areas of knowledge that are relevant to design, giving students a comprehensive and integrated view of the various elements that compose a product. However, an instrument that facilitates access to knowledge should not be seen as a barrier to creativity of designers, but a stimulus to the search for new solutions, as the designer can start his work with the knowledge of already existing solutions.

It is also important to note that although the knowledge base is focused on the furniture sector, actually there is no assumption that it is used only for furniture designs because many solutions can be used in other contexts. As the base expands it is believed that it will become increasingly applicable to other design areas. Our goal was to demonstrate that ProductMap is able to organize and facilitate access to knowledge in any area within the realm of product design.

\section{References}

BAILEY, K. D. Typologies and taxonomies: an introduction to classification techniques. Sage Publications, London: Thousand Oaks, 1994.

BUSCH, P. Tacit Knowledge in Organizational Learning. Hershey: IGI Publishing, 2008. http://dx.doi. org/10.4018/978-1-59904-501-6 
BÜRDEK, B. E. Design: History, Theory and Practice of Product Design. Boston, 2005.

BUZAN, T. How to mind map. Thorsons, 2002.

CROSS, N. The nature and nurture of design ability. Design Studies, v. 11, n. 3, p. 127-140, 1990. http://dx.doi. org/10.1016/0142-694X(90)90002-T

DHINDSA, H. S.; KASIM, M.; ANDERSON, O. R. Constructivist-Visual Mind Map Teaching Approach and the Quality of Students' Cognitive Structures. Journal of Science Education Technology, v. 20, p. 186-200, 2011. http://dx.doi.org/10.1007/s10956-010-9245-4

EILOUTI, B. H. Design knowledge recycling using precedentbased analysis and synthesis models. Design Studies, v. 30, n. 4, p. 340-368, 2009. http://dx.doi.org/10.1016/j. destud.2009.03.001

HILL, M.; HILL, A. Investigação por questionário. Lisboa: Edições Sílabo, 2002.

HUNTER, E. J. Classification Made Simple: An Introduction to Knowledge Organization and Information Retrieval. Ashgate Publishing, 2009.

KOKOTOVICH, V. Problem analysis and thinking tools: an empirical study of non-hierarchical mind mapping. Design Studies, v. 29, n. 1, p. 49-69, 2008. http://dx.doi. org/10.1016/j.destud.2007.09.001
LAWSON, B. How designers think. Routledge, 2005.

MUller, W. Order and Meaning in Design. Purdue University Press, 2001.

NAVEIRO, R.; BRÉZILLON, P. Contextual Knowledge in Design: the SisPro Project. Journal of Decision Systems, v. 12, n. 3-4, p. 253-270, 2003.

NUNES, L.; TÁLAMO, M. Da filosofia da classificação à classificação bibliográfica. Revista Digital de Biblioteconomia e Ciência da Informação, v. 7, n. 1, p. 30-48, 2009.

OKADA, A. Cartografia Cognitiva: novos desafios e possibilidades. 2004. Available from: <http://www.projeto. org.br/cartografia/texto2.htm>.

OXMAN, R. Prior knowledge in design: a dynamic knowledgebased model of design and creativity. Design Studies. v. 11, n. 1, p. 17-28, 1990. http://dx.doi.org/10.1016/0142694X(90)90011-Z

TRISTÃO, A.; FACHIN, G.; ALARCON, O. Sistema de classificação facetada e tesauros: instrumento para organização do conhecimento. Ciência da Informação, v. 33, n. 2, 2004. http://dx.doi.org/10.1590/S010019652004000200017

W ORLD IN T E L L E C T UAL PROPERT Y ORGANIZATION - WIPO. What is WIPO? 2011. Available from: <http://www.wipo.int/about-wipo/en/what_is_wipo. html>. 